\title{
REFRAMING WORKING, RETHINKING LEARNING: THE FUTURE SKILLS TURN
}

\author{
Ulf-Daniel Ehlers, Laura Eigbrecht, Baden-Württemberg Cooperative State University \\ Karlsruhe, Germany
}

\section{Abstract}

Research on Future Skills is one of the current hot topics in education, management and organizational research. In times of global networked organizations and steadily accelerating product cycles, the model of qualification for future jobs seems debatable. Can we really prepare graduates and employees for the future by the predominant model of knowledge acquisition? Do we already have adequate concepts for competence development in higher education and work environments? An international study led to the identification of the change processes that the working and learning world are undergoing as well as of the Future Skills that will be needed in highly emergent future contexts - including digital competences, but transcending them. This calls for new strategies and concepts concerning structural, teaching and learning aspects and a new way of embracing lifelong learning concepts. "Future organizations" have been identified that have already set out for dealing with those new demands. By learning about their innovative approaches concerning employees' competence and skills acquisition, a veritable turn away from specialist knowledge and towards Future Skills can be observed - and cannot be ignored by higher education. Keywords: Future Skills, Higher Education, Learning, Competence, Delphi Survey, Education Research

\section{Introduction to the Field of Future Skill Research}

The NextSkills (www.nextskills.org) studies show that a veritable turn away from specialist knowledge and towards Future Skills can be observed: Research on Future Skills is one of the current hot topics in management and organizational research (Ehlers, 2020; Ehlers \& Kellermann, 2019). In times of global networked organizations and steadily accelerating product cycles, the prevailing model of qualification for future jobs seems debatable. The vast majority of employers surveyed for the "Future of Jobs Report" of the World Economic Forum (WEF, 2018), released in 2018, expects that by 2022, the skills required to perform most jobs will have shifted significantly. 
Can graduates really be prepared for the future by predominantly acquiring knowledge? Do we already have adequate concepts for competence development in higher education? Or do we need something new, something radical? Our research shows that the discourse on Future Skills is becoming more prominent (Ehlers, 2020). Examples are lists of skills for living and working in 2030 (OECD, 2018) or the analysis of work area-related qualifications (Deming, 2017) (for a complete analysis of the state-of-the-art research see Ehlers, 2020). What is needed, however, is to go a step further and conduct in-depth research.

Starting point for the research on Future Skills reported in this paper is an analysis of factors which influence our lives, the way we work and live, learn and develop. Such descriptions, by dealing with the future, carry a certain degree of vagueness, while being as precise as possible in capturing aspects that can be seen as influencing factors for the future: future ways of living, future ways of work, future ways of learning, etc. (e.g. OECD, $2017 ; 2018 ; 2019)$. Analysing the currently existing papers on important skills and abilities for the future work life, at least two converging primary factors crystallize:

- Increasingly fast technological advancements and their effects on all spheres of our lives, work and societies lead to an excess of information and options.

- Increased global cooperation, exchange and communication are no longer an option but a necessary ingredient of every process of society, work and life.

Resulting from that, a number of connected changes can be observed:

- Due to the changes in work structures, there will be a new demand for (higher) education studies and innovation in learning pathways and qualification structures including certification and credentialing schemes.

- The rising demand for higher education will turn industrial societies into education societies where education is the means by which one can manage risks.

- The very essence of how learning and studying is organized is evolving into new concepts - from static to reflection in action in complex situations.

In order to find reference models which are capable of capturing the intertwined and networked nature of these developments, we base our NextSkills studies in ecosystem theory and cybernetics. Combining these approaches with an educational science as well as with a sociological point of view, our research is rooted in the assumption that there are ongoing changes within the structure, nature, and profile of competences and skills (Ehlers, 2020). Our studies show that the changing skill requirements can be described and analysed.

In order to be able to research the articulation, extent, nature and contexts of such Future Skills, we designed a threefold long-term research project, starting in 2015, called "Future Skills - Future Learning and Future Higher Education”. In this paper we shortly outline 
the methodology of the studies to arrive to the 17 Future Skills profiles. We then report about the Future Skills turn and state good practice examples of organizational concepts to support the development of Future Skills with students and employees.

\section{Methodological Design and Research Context of the Delphi Study}

The research focus is on identifying Future Skills in a broad and holistic sense, incorporating digital skills but going beyond them, and determining which changes in the working world are causing these new skill demands. Moreover, we identified so-called future organizations (future organizations are defined as organizations which already have a well-developed and explicitly formulated understanding for the promotion of the capacity to act) that already promote their employees' skill enhancement in innovative ways which could inspire higher education. Our research aims at defining Future Skills, the way they are being perceived and promoted in so-called future organizations, as well as asking how higher education can support their development (Ehlers, 2020). In order to address this complex field systematically, we asked three questions within three different, but interrelated areas:

- Future Skills: Which skills are necessary for future employees? Which skills will be necessary to shape the future and society in a sustainable way?

- Future learning concepts: How can organizations and firms support the development of Future Skills (learning and management approaches)?

- Future higher education: How can we design higher education concepts in order to support the development of Future Skills?

Part 1 of the research initiative was about identifying innovative and future-oriented future organizations, based on their human resource development strategies. In part 2 of the research, we analysed the nature of these competence concepts and the competence demands of the future organizations through in-depth interviews and we were able to model a set of 17 competence profiles which we refer to as Future Skills, each containing a number of sub-competences and embedded in a three-dimensional competence frame. In part 3, in order to validate our findings and to determine the impact of the demand for Future Skills on higher education, we designed an international Delphi study, drawing on the assessments and opinions of almost 50 experts from all over the world. The experts were asked to reflect and evaluate within three areas which were identified as important for future higher education: (a) drivers of change shaping future higher education, (b) scenarios of future higher education, and (c) Future Skills. For each of the areas we were interested in the degree of relevance of the respective issues, as well as in the experts' opinion about when they would gain relevance. 
Seventeen Future Skills profiles (Figure 1), each containing further subskills, have been defined and can be differentiated in three skills dimensions as follows:

- The first Future Skill dimension is the subjective dimension of Future Skills profiles. It is relating to an individual's subjective, personal abilities to learn, adapt and develop in order to improve its opportunities to productively participate in tomorrow's working world, actively shape it and get involved with designing societies to cope with future challenges. It contains seven Future Skill profiles.

- The second Future Skill dimension is relating to an individual's ability to act in a self-organized way in relation to an object, a task or a certain subject-related issue. It is emphasizing a new understanding of knowledge, going beyond pure expertise and towards connecting knowledge with motivation, values and the capacity to act in the concerned field of knowledge. It contains three Future Skill profiles.

- The third Future Skill dimension is relating to an individual's ability to act selforganized in relation to its social and organizational environment. It is emphasizing the individual's dual role as the curator of its own social portfolio of membership in several organizational spheres of rethinking organizational spaces and recreating organizational structures for the future. It contains five Future Skill profiles.

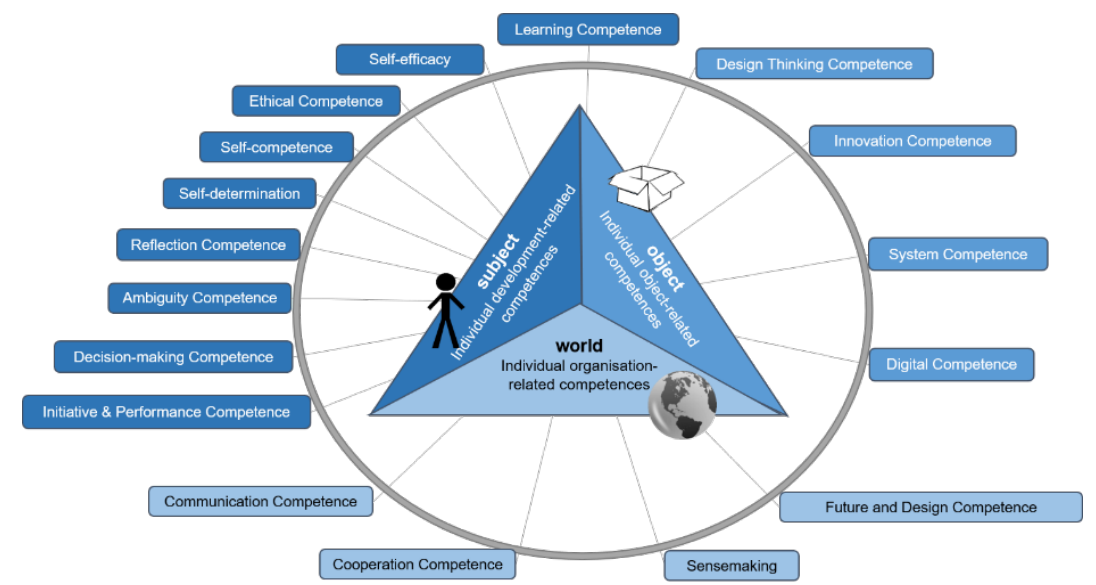

Figure 1. The 17 Future Skill profiles

\section{The Future Skills Turn in Practice}

\section{Leadership and learning in networked systems}

William Ross Ashby's works “An Introduction to Cybernetics” (1956) and "Design for a Brain" (1952) have been influential in the sciences of complex systems since their appearance in the 1950s, when they were known as cybernetics. Ashby's law bears his name and provided the scientific basis for the "homeostatic" principle and the principles of self-organisation. The "Law of Requisite Variety" is one of the central insights of cybernetics (Ashby, 1956). 
This law states that a system that controls another can compensate the more for disturbances in the control process the greater the variety of its action: the greater the variety of a system, the more it can reduce the variety of its environment by controlling. Consequently, the variety of the control system must be at least as great as the variety of the malfunctions that occur in order to be able to control it. Following this idea, this means that whenever it is a question of dealing successfully with highly complex and dynamic situations, the acting system must have at least the same complexity and dynamics as the system in which action takes place. Transferring this thought to today, it means: As markets continue to network, it becomes more and more important to allow and promote free networking within one's own organization. Otherwise, one risks getting lost.

The very meaning of leadership in companies and organisations then changes: it no longer means thinking ahead or steering the activities of employees, but ensuring that the people in the company can develop the necessary Future Skills in order to recognise interrelationships and thus be able to organise themselves in line with market requirements. It can be observed that the individual has an increasingly greater responsibility within the organisation. Less responsibility can be transferred to central management structures. The question of which Future Skills are actually important and needed in order to successfully work on the respective tasks in the "network organisation" can only be answered in a very personalised way and in the respective context - and the learning of these skills must also be done by the individual itself.

Examining today's institutions, this connection becomes immediately apparent. Those interviewed for the Future Skills Study are aware that the development of the necessary skills is so volatile and constantly changing that 80 percent of the necessary learning takes place "on the job" (Ehlers, 2020). The externally organised, formal and explicit training plays an ever less important role. The ability of one's own individual information management is not only a question of subjective knowledge management, i.e. how one organises one's own knowledge area. It is also about having the ability to validate data and information.

The French philosopher and mathematician Marquis de Condorcet already pointed out an important additional condition in the $18^{\text {th }}$ century. The Condorcet jury theorem states: "If the amount of knowledge distributed in the minds of the set of decision-makers involved in an estimation task is a little below chance, then the hit rate of the overall decision is extremely low". If, on the other hand, the individual's knowledge is only a little above chance, then the group will rock itself to a surprisingly high marksmanship. With regard to organisations, this means that the distributed knowledge is limited in principle by information monopolies, relationship networks or hierarchical thresholds. It is therefore an important task to ensure that this does not happen and that knowledge is freely 
available and without the typical knowledge restrictions (e.g. information monopolies) in the organisation.

\title{
The Relativity of Knowledge and Expertise
}

With regard to professional competence and knowledge, the Future Skills Study shows that many organisations are increasingly realising that the ability to take the initiative, i.e. to follow up on and implement the impulses and ideas arising individually from one's own initiative, and the self-competence closely associated with this, plays an equally important, if not perhaps even more important role than specialist knowledge. However, this polarization of knowledge on the one hand and competence on the other is only an apparent contradiction - knowledge being a central building block for competence. Competence, however, goes far beyond knowledge. Self-competence, for example, can be described as the

\begin{abstract}
"Willingness and ability as an individual personality to clarify, think through and assess the development opportunities, demands and restrictions in family, career and public life, to develop one's own talents and to draw up and further develop life plans. It includes qualities such as independence, critical ability, self-confidence, reliability, sense of responsibility and duty. This includes in particular the development of well thought-out moral concepts and the self-determined attachment to values."
\end{abstract} (KMK, 2011)

This insight is often the subject of a seeming contradiction, which repeatedly emerges in the recent debate about knowledge/expertise vs. action competence and skills and requires fundamental reflection. It is expressed in statements by large Tech-Companies (Times Higher Education, 2015) about the relativization of formal certificates as well as in controversial debates among teachers on the question of whether competences are a realistic goal for learning processes at all, when there is so much knowledge to learn at first.

In the organizations surveyed, personnel development instruments were increasingly geared towards supporting individual competence development and in particular the development of subject competences. The development of self-organized learning as the future competence par excellence in turn requires new and special models of training, support and development for employees.

\section{Future Skills in Practice}

A veritable turn towards Future Skills can be observed. This is also expressed in the instruments that are increasingly being used in human resource development. In 
personnel development, more and more importance is attached to how cooperation and networking can be promoted. This is also reflected in the range of continuing training opportunities and measures, less catalogue-oriented but increasingly aimed at networking - and thus at self-organisation. This is expressed quite practically, for example, in the fact that a human resources manager reports that today there are about 200 offers of personnel development per year, and 80-85 percent of these are organized as colleague trains colleague (medium-sized medical device manufacturer). In some organisations there are also explicit departments that emphasise the importance of learning for work and interlink both issues, for example a learning and work team in one of the participating organisations (large drugstore chain).

The shift in Future Skills - away from specialist knowledge towards Future Skills - is also reflected in the fact that coaching, consulting and mentoring are playing an increasingly important role alongside traditional personnel development tools. Coaching stands for open-ended and solution-focused support of personal contexts, consulting for a format in which the main focus is on targeted support for a given problem, while mentoring can also take place between colleagues with different expertise. The dissolution of the boundaries between the private and the professional is a trend-setting development.

The following practice examples briefly illustrate how organizational structure, values, leadership and communication structures must interact in order to build an organizational culture for Future Skills.

\section{The Competence workshop: A method to strengthen networking and self-organization}

Employees of all departments and hierarchical levels can register in a one-year competence workshop. The aim of the competence workshop is to tackle a personal learning or development task. This format also serves to support networking of employees within the organization. A new network of employees is created, which runs through the entire organization and connects employees who have not previously had any contact or connection with each other.

\section{The end of instruction: Learners and Students as Experts}

A large drugstore chain adopts the view that learning does not function through instructing or teaching, but is a self-active and self-controlled process. Trainers are learning facilitators, certificates or examinations are documented in a personal learning passport, learning facilitators receive special training as learning facilitators, which is intended in particular to support learning as a self-organized process. Similarly, a world market leader in the IT service sector is turning the tide - it is no longer trainees and (dual) students who need to be trained and further educated, but the company wants to benefit from the perspectives of young people and their unbiased view. Individual departments can apply 
to students with project ideas within authentic problem contexts, i.e. real problems that are relevant for the company.

\section{Creativity in distributed teams}

Experts of a globally leading technology group point out that it is important for an organization to build competence on how skills can be put together as "shared expertise" in departmental and project teams - sometimes even worldwide. The approach is based on the point of view of the organization it is important to have a complete spectrum of competences distributed within a team as far as possible.

\section{Flexibilization and self-organization}

In all surveyed organizations, learning and working take place in contexts that allow flexibility in workflows, roles, function descriptions and definitions. Examples include the organization of working time on the shop floor or the abolition of working time regulations (for a large chemical group).

\section{Create space, change perspective, enable innovation and creativity}

How do you get the members of an organization to think beyond their particular situation and develop suggestions for new products, new business ideas or processes? A world market leader in the medical devices sector has initiated an internal competition for this purpose. All members of the company were invited to submit suggestions to the management on what a new corporate strategy could look like. From all the proposals, some were selected that were particularly far-reaching and diverse. Those who had brought them in were then sent into a seven-week retreat as a team.

\section{Strengthening self-organization and self-responsible learning}

In cooperation with a University of Education, a large chemical company has developed its own approach to strengthening learning skills. A radical change has been initiated, away from the structured presence in continuing education towards self-responsible learning via e-learning in virtual worlds where employees themselves are increasingly becoming the managers and designers of their own learning experiences.

\section{Empowering personalities and self-confidence}

How can employees strengthen their own self-confidence in order to enhance Future Skills learning? Targeted coaching measures are required that lead to more self-organization ability, autonomy and the ability to act, especially in contexts in which employees have to deal more and more with uncertainty and ambiguity. An organization participating in the NextSkills study conducts theatre workshops with employees for this purpose. It is often a matter of bringing together exactly those in organizations that have nothing else to do with each other, i.e. acting across departments or business units, often in completely new and 
Ehlers, U.-D., \& Eigbrecht, L.

Reframing Working, Rethinking Learning: The Future Skills Turn

external environments, in order to strengthen employees' self-confidence, self-competence as well as autonomy and performance motivation.

Creating (free) spaces

Development needs freedom, needs recognition and the knowledge that one's own commitment is well received and that design proposals can be implemented. One of the organizations participating in NextSkills lives this as a practical reality, taking their employee suggestion scheme seriously. Employees can contribute their ideas online and then gradually implement them through participatory selection processes. The identity of the individual employees with their actions within their organization can thus be further strengthened.

\section{FUSE: Participation-oriented strategy development}

An example from the academic world shows what real participatory design of future organizational strategies can look like. FUSE was a crowdsourcing initiative of Dublin City University to develop key ideas for the university's future five-year strategy - together with all stakeholders of the university. FUSE is conceived as a brainstorming event in which all 17,000 students, 80,000 alumni and 1,200 university members had the opportunity to contribute their ideas online - for 30 hours. It is a hallmark of future organizations to allow participation in design processes.

\section{Conclusion}

A veritable turn away from specialist knowledge towards Future Skills can be observed not only in research but also in working environments and organization's approaches to competence and lifelong learning. So-called "future organizations" already take innovative approaches in order to foster their employees' Future Skills learning and to deal with new work-related requirements. Higher education institutions can learn from this in order to also become future organizations, preparing their graduates for the challenges of uncertain and emergent future work and society contexts. This calls for new strategies and concepts concerning structural, teaching and learning aspects and a new way of embracing lifelong learning concepts.

\section{References}

Ashby, W. R. (1956). An introduction to cybernetics. London: Champman \& Hall.

Deming, D. J. (2017). The growing importance of social skills in the labor market. The

Quarterly Journal of Economics, 132(4), 1593-1640. doi:

https://doi.org/10.1093/qje/qjx022

Ehlers, U.-D. (2020). Future Skills - Future Learning and Future Higher Education.

Wiesbaden: Springer. 
Ehlers, U.-D., \& Kellermann, S. A. (2019): Future Skills. The Future of Learning and Higher education. Results of the International Future Skills Delphi Survey. Karlsruhe. Retrieved from https://nextskills.org/future-skills-report2019/

Kultusministerkonferenz (KMK). (2011). Handreichung für die Erarbeitung von Rahmenlehrplänen der Kultusministerkonferenz für den berufsbezogenen Unterricht in der Berufsschule und ihre Abstimmung mit Ausbildungsordnungen des Bundes für anerkannte Ausbildungsberufe. Berlin: Sekretariat der Kultusministerkonferenz.

OECD (2017). Future of Work and Skills. Retrieved from https://www.oecd.org/els/emp/wcms_556984.pdf

OECD (2018). The Future of Education and Skills. Education 2030. Retrieved from https://www.oecd.org/education/2030/E2030 Position Paper\%20(05.04.2018).pdf

OECD (2019). Trends Shaping Education 2019. OECD Publishing: Paris. Retrieved from https://doi.org/10.1787/trends_edu-2019-en

Times Higher Education. (2015). Earnest and Young Drops Degree Classification Threshold for Graduate Recruitment. Retrieved from https://www.timeshighereducation.com/news/ernst-and-young-dropsdegreeclassification-threshold-graduate-recruitment

World Economic Forum (WEF). (2018). Towards a Reskilling Revolution: A Future of Jobs for All. Retrieved from http://www3.weforum.org/docs/WEF_FOW_Reskilling_Revolution.pdf 